\title{
Evolving schemes of interpretation: Investigating the dual role of architectures in new product development
}

Thomas Magnusson and Nicolette Lakemond

\author{
Linköping University Post Print
}

Tweet

N.B.: When citing this work, cite the original article.

Original Publication:

Thomas Magnusson and Nicolette Lakemond, Evolving schemes of interpretation: Investigating the dual role of architectures in new product development, 2015, R\&D Management.

http://dx.doi.org/10.1111/radm.12142

Copyright: RADMA and John Wiley \& Sons Ltd. http://onlinelibrary.wiley.com/

Postprint available at: Linköping University Electronic Press

http://urn.kb.se/resolve?urn=urn:nbn:se:liu:diva-119206 


\title{
Evolving schemes of interpretation: investigating the dual role of architectures in new product development
}

\begin{abstract}
Should product architectures be considered inputs to - or outputs from - new product development (NPD)? Whereas the mirroring hypothesis suggests the former, NPD stage-models suggests the latter. Elaborating on these conflicting propositions, this paper analyses the relationships between product architectures and development processes in NPD projects. The analysis demonstrates how project managers use product architectures to interpret their tasks and devise appropriate responses to perceived challenges. Thus, architectures provide useful linkages between knowledge development and organizational change in $R \& D$ organizations.
\end{abstract}

Keywords: product development; product architecture, development processes; modularity; concurrent process; integrative process

\section{Introduction}

Product architectures are schemes that describe how components in a product system interact (Ulrich \& Eppinger, 2011). Such schemes play important roles in shaping new product development (NPD) processes and R\&D organisations (Ulrich, 1995). In particular, the use of modular product architectures with standardized interfaces between different components has been proposed as a promising strategy, which facilitates cost reduction, flexibility and reduced time-to-market (Baldwin \& Clark, 1997; Mikkola, 2003; Mikkola, 2006; Ro et al., 2007). To attain these benefits, the so-called "mirroring hypothesis" suggests that R\&D organizations should be designed as reflections of the systems they develop (Sanchez \& Mahoney, 1996). Following the mirroring hypothesis, product architectures thus determine effective means for task partitioning, information exchange, and knowledge sharing.

However, there is contradictory support for the mirroring hypothesis (Hoetker, 2006; MacCormack et al, 2012). According to (Cabigiosu \& Camuffo, 2012), firms can only fulfil the promises of modularization if they can specify architectures ex-ante and keep them stable. Still if one regards product development as a process that not only applies existing knowledge but also generates new knowledge (Vincenti, 1990), it will be difficult to consider the architecture as a pre-specified and stable entity. Indeed, several studies have pointed at the uncertain and dynamic nature of NPD, where deviations from initial specifications and expectations constitute the norm rather than the exception (Eisenhardt \& Tabrizi, 1995; Ingvarsson Munthe et al., 2014; Stockstrom \& Herstatt, 2008). Under such circumstances, the mirroring hypothesis becomes an ambiguous concept.

Previous management studies have primarily focused on strategic aspects of architectures, where relationships between product architectures and the boundaries of the firm have been extensively debated (Becker \& Zirpoli, 2003; Brusoni et al., 2001; Sanchez \& Mahoney, 1996; Sushandoyo \& Magnusson, 2012). However, given a strategic decision on product architecture, there are still many operational issues to resolve (Zirpoli \& Becker, 2011). According to Zirpoli and Becker (2003, p. 38): this "stimulate[s] further research aiming at a systematic connection and integration of strategic aspects of innovation management and its operational aspects."

With the aim to explore the operational aspects of product architectures in NPD, this paper addresses the following question: Given the dynamic nature of NPD projects, how can product architectures guide development processes? The paper emanates from a knowledge- 
based theory of organizations (Brusoni et al., 2001; Grant, 1996; Okhuysen \& Eisenhardt, 2002). Following this theory, a prime task for NPD is to develop and integrate different pieces of specialized knowledge into a coherent whole (Dougherty, 1992; Enberg et al., 2006; Marsh $\&$ Stock, 2006). The next section of the paper outlines the theoretical framework, which elaborates on the relationships between product architectures and NPD processes. A subsequent section then explains the research methods. Thereafter, an empirical section describes the cases, and an analysis section discusses and compares the case observations in the light of the framework. A concluding section summarizes the main findings, and outlines managerial implications of the study.

\section{Product architectures and NPD processes}

Strategic management literature - advocating the mirroring hypothesis - and engineering design literature - advocating NPD stage-models - arrive at conflicting propositions. On the one hand, strategic management literature proposes that product architectures constitute important inputs to NPD, which engineers use as a basis for their work. On the other hand, engineering design literature proposes that product architectures emerge during early stages of development. Hence, they constitute important outputs from NPD activities.

Informed by already available concepts such as 'near decomposability' (Simon, 1962) and 'loosely coupled systems' (Orton \& Weick, 1990), the characteristics of technical system architectures have drawn the attention to how product designs may affect the design of organizations (Ethiraj \& Levinthal, 2004). More specifically, strategic management scholars have proposed that product designs guide firms to manage knowledge flows in product development processes (Sanchez \& Mahoney, 1996). Emanating from the assumption that stable interfaces between components reduce the need for integration, Sanchez and Mahoney argue that (1996, p. 73) "modular system architectures of many types may be a new dominant design for achieving increased flexibility and inter-organizational connectivity among broadly de-integrating organizations." Following this line of argument, modular architectures make it possible to use the product as a basis for decomposition of the task, assigning different teams to different components in the product system (Baldwin \& Clark, 1997). These teams thus focus their activities on separate sub-tasks, conducting meetings with heads of engineering, marketing and manufacturing departments; analyzing action items from team-staff meetings; reviewing test and verification reports; and evaluate customer reaction reports to product concepts (Lynn et al., 1999). Hence, module teams provide channels for knowledge flows among specialized engineers within the teams (cf. Okhuysen \& Eisenhardt, 2002). The problem-solving processes of different teams emerge concurrently, guided by clear, consistent and stable specifications.

By contrast, with integral architectures, interdependencies in the product systems are unpredictable. Because cause-and-effect relationships between actions and outcomes are uncertain, there is a continuous need to assess systems-level impacts of component-level decisions (Iansiti, 1995). The combination of unpredictable interdependencies and uneven rates of change in component technologies will augment this need for system integration (Brusoni et al., 2001). In NPD projects, the instance of integral architectures results in challenges of both cross-functional and cross-system integration. Moreover, there is a need for feedback loops from later stages to earlier stages in the development process (Nightingale, 2000). Consequently, integral architectures put high demands on the integrative capabilities of the organization (Filippini et al., 2004; Kessler \& Chakrabarti, 1999). Important decisions relate not only to how organizations can support integration, but also the point in time when 
integration should occur (Zirpoli \& Becker, 2011). Cross-functional teams may facilitate component-level problem solving, but tests and prototypes are required to facilitate systemlevel feedback (Eisenhardt \& Tabrizi, 1995; Kessler \& Chakrabarti, 1999). Product development thus benefits from processes, which oscillate between component-level acting and system-level interacting (Enberg et al., 2006).

The mirroring hypothesis suggests that different NPD processes follow different product architectures. Firms that develop modular products are likely to develop structures and routines that support concurrent, component-level processes. By contrast, firms that develop integral products are likely to develop structures and routines that support integrative processes. These alternatives are polar extremes and it is important to note that NPD processes often take intermediate forms, e.g. solving interface problems without having to encompass the complete product system (cf. Ingvarsson Munthe et al., 2014).

The mirroring hypothesis has been questioned though. According to (Colfer \& Baldwin, 2010) p. 17) "nothing prevents a tight-knit team or an individual with adequate knowledge from creating a design made up of largely independent components". Hence, a modular architecture may very well constitute the outcome of an integrative process (Cabigiosu \& Camuffo, 2012; MacCormack et al., 2012). Engineering design literature describes this in terms of NPD stage models (Ullman, 2009; Ulrich \& Eppinger, 2011). Such models encompass early stages of product definition, concept design and systems engineering, as well as later stages of detail design, testing, refinement, verification, and production ramp-up. Specifications, which define product system characteristics and interfaces, constitute important outcomes of the early stages as these facilitate de-coupling of tasks (Eppinger, 1991; Kusiak, 2002). This early work is important to avoid deviations with system-wide implications during later stages (Ingvarsson Munthe et al., 2014). Hence, integrative processes are likely to be prevalent as long as architectures remain unsettled during the early stages of product definition, concept design and systems engineering. Concurrent processes, on the other hand, will be more prevalent during the later stages.

\section{Research methods}

The empirical study contains in-depth case studies of NPD projects executed at three manufacturing firms. A longitudinal research design allowed us to develop an understanding of the cases during a period of more than two years.

\subsection{Case selection}

To enhance the study's external validity (Gibbert et al., 2008), a clear rationale guided the case selection. First, the selected firms operate in relatively mature markets and a simultaneous focus on effectiveness and efficiency characterize their product development. Thus, we were able to exclude explanations based on differences in product life cycles (Campagnolo \& Camuffo, 2010). Second, the products embody different kinds of engineering, which meant that it was possible to illustrate NPD processes encompassing specialized knowledge bases. In particular, since the products are mass-produced, the studied projects incorporated both product and production engineering. Third, formal stage-gate models (Cooper, 1994; Cooper, 2008) provide a basic structure for product development at the three firms, providing opportunities for comparability across the cases. The projects were recently finalized or in a finalization stage as we initiated the studies. 


\subsection{Data collection}

In total, we made 43 semi-structured interviews with project managers, line managers and engineers at the firms. Even though the study focused on three specific NPD projects, the limited size of the firms made it possible to develop a comprehensive understanding of the historical and organizational contexts (Engwall, 2003), in which the projects operated. A majority of the respondents was managers and engineers from $R \& D$, but we also interviewed respondents from other departments. Guided by open-ended questions, the interviews took between one and a half and three hours. During the interviews, the respondents explained their respective roles in the organization and recalled critical events and decisions during the execution of the case study projects. In order to avoid problems related to bias, poor recall and inaccurate articulation (Yin, 1994), we also studied available project documentation and archival records such as project plans, resource plans and project evaluation reports.

\subsection{Data analysis}

The data analysis followed the three flows of activity suggested by Miles and Huberman (1994), i.e. reduction, display and conclusion drawing/verification. We drafted comprehensive narratives of the studied projects based on multiple readings of interview transcripts and notes, as well as project documents and archival data. Informants from the participating firms corroborated the narratives. In refining these narratives, we noted that interview respondents did not calculate the level of modularity as an absolute property, but they still referred to the characteristics of product architectures in the justification of their way of managing the projects, using terms such as concept, system, module, interface, dependency, relationship and integration. Thus, we focused the data analysis on the particular use of these terms. Comparisons between predicted patterns from the literature and the emerging patterns from the case studies (Yin, 1994) guided the analysis. Accordingly, we elaborated conclusions based on supporting and contradicting evidence for our developing ideas. Moreover, we organized three consecutive one-day workshops, in which managers from the three firms participated. These workshops helped to confirm the case study findings, deepen our understanding of the cases and thus increase internal validity (Gibbert et al., 2008). Another outcome of this interactive research was an assessment tool that provided the firms with the possibility to assess major challenges in their future projects (Lakemond et al., 2013). By testing and evaluating this tool in dialogue with managers, we could further validate our understanding of the case studies.

\section{Case studies}

The three studied NPD projects were important parts of the continuous innovation efforts at the firms. Still, the development tasks represented significant challenges for the R\&D organizations. Upon request from the firms, we use three pseudonyms for the cases: Outdoor, Home, and Automotive.

\subsection{Outdoor}

Outdoor develops and produces products for outdoor use such as chainsaws, lawn mowers and trimmers. Many of these products have an internal combustion engine as its core component. Whereas the firm markets its products worldwide, North America is by far the most important market. The case study project aimed at developing a new chainsaw with a 2stroke engine. The development started because of pending regulations in North America, which stipulated a 50\% reduction of the exhaust emissions. 
The pending regulations provided the project with a very sharp deadline. Series production had to commence 4 years and 3 months after project start. If the project failed to deliver, Outdoor could lose its complete sales on the North American market, which amounted to about one-third of the firm's total production of chainsaws. Moreover, the pending regulation imposed strict and very challenging performance requirements. A significant technological leap was necessary to fulfill these requirements. Although a separate R\&D laboratory had made a few tests, the requisite technology remained unverified as the project started. With the ambition to reduce project risks, the project manager established a separate team with the task to develop the new engine, comprising the new and still unverified technology. In order to refrain from changes that could delay engine development, management instructed the engineers in other teams to keep their designs as stable as possible.

In some respects, it may even have been easier than other projects. We already had modern products in this segment, so we did not have to take too large risks. If we were to fail on something, it was to be the engine (. . .). Many other projects have been forced to reconsider everything and redesign all the modules. In this case, we decided to use conventional technology, things that we already had. (Project manager)

The engine team could verify the functionality of the new engine technology about one year after project initiation. However, they discovered a problem related to the fuel supply, which did not provide appropriate amounts of fuel for engine speeds between 6000 and $14000 \mathrm{rpm}$. The engineers eventually solved the problem through combined simulation and trial-and-error activities.

As the project turned its focus to production, the project manager had to facilitate a timeefficient hand-over. In previous projects, the R\&D department had been responsible for testseries production, but in this project, the production department obtained this responsibility. Production engineers established an exclusive test assembly line, which they located in the assembly plant.

They made the assembly lines and test stations - the complete package - and they did this really well. Moreover, there was a significantly raised level of engagement, and more resources. That was extremely important. (R\&D project coordinator)

The exclusive test assembly line became an arena in which engineers from various $R \& D$ teams could meet with production engineers and production staff to identify and resolve technical problems. The project also used it for education and training of assembly operators and production personnel. Hence, integration between product development and production essentially took place at the test line. The project followed a stepwise process for production hand-over, with a strict division between test series and production pilot run, making it possible for preparatory activities to follow a structured process where lessons learned from assembly line tests were fed back to engineers for corrections. Managers and engineers involved in the project found that this made production preparatory activities more timeefficient than in previous projects. Thus, the project could complete production hand-over at an acceptable point in time.

In retrospect, managers and engineers at Outdoor agree that the project was successful; some respondents even stated that it was the most successful project ever at the firm. Above all, the non-negotiable emission requirements and deadline resulted in extraordinary discipline, focus and commitment within the organization. In the end, the project managed to meet the 
stipulated requirements and deliver in time. The only parameter that failed to meet the specification was the product weight, which ended up about 300 gram above the target value. Several respondents also pointed at the novel way of organizing production preparations as an important success factor, and a possible role model for future NPD projects in the firm.

\subsection{Home}

Home develops and manufactures sewing machines. Similar to Outdoor, North America is the most important market, with about $60 \%$ of Home's sales volume. The sewing machine traditionally relies on precision mechanics, but recent developments of advanced electronics and computer controls have made it possible to add functionality such as embroidery capabilities. This has resulted in further enhanced demands on accuracy and precision. In addition, the amount of embedded software has increased dramatically. As a result, today's most advanced sewing machines rely just as much on software as on mechanics.

Home initiated the studied project with the ambition to replace their existing top model in the high-end segment. Initially the project was to base much of the design on existing hardware and focus on software development. This was the first NPD project, which had such a clear software focus. Senior management scheduled about one and a half years for the project, but an assessment of the amount of software development needed to reach the desired functionality showed that the project would require additional time. This opened up for hardware changes in order to make the machine more attractive and up-to-date. The senior management thus revised the initial specification and the development turned from delimited software upgrade to a major project, comprising a complete redesign with new illumination technology, updated electronics, new graphical display and USB-port, separate winding motor, and new plastic covers all over the machine. This project would involve almost the entire R\&D department for a period of three and a half years.

The project manager organized the project in a number of module teams, largely guided by the existing organizational structure of the R\&D department. Each team was responsible for the development of different components or sub-systems, such as mechanics (interior and exterior), software, and electronics.

We had a core group with a project manager and module leaders and we had our own meetings within the modules. We were about 5-6 module teams. (Software team leader)

Apart from engineers from R\&D, the teams involved personnel from Marketing, Production, and Quality control. As new technological options emerged during the project, senior managers changed the specifications. However, the development engineers increasingly realized that the introduction of new component technologies had implications also for other components. The responsibility to facilitate communication between engineers in the different module teams fell onto the project manager.

It is a common problem that we redefine projects continuously due to changed prerequisites. (...) This is where the project manager comes in. To run a project where everything runs according to plan is not difficult. Anybody can do that. Nevertheless, the project manager is important to secure communication and observe relationships when you redefine. (Line manager mechanical design) 
The line manager further noted that project managers would be useless in the absence of interdependency problems. Approaching the finalizing development stages, senior managers froze the specification, aiming for launch at an upcoming sew fest event. ${ }^{1}$ As the project entered verification, the software team felt severe time pressure because repeated alteration of specifications had delayed their work. Still, the test engineers needed the software to run the prototype. When they eventually could run the prototype, they discovered that the electronic circuit board was sensitive for electro-static discharge from the electric motors. This resulted in late modifications of the electronics, increasing the need for feedback loops between the teams.

We could not implement any software in the first production machines in order to test them. Thus, we could not run the machine. We would have needed the software earlier. Moreover, the electronics were sensitive to electrostatic discharge. The machine disturbed itself and we had to redesign the electronics to protect it better. We discovered this late because we could not run the machine without software. The software team gave us their schedules but we did not sufficiently specify what they were supposed to deliver. For example, we did not know that we had to control the illumination. We knew from the start that systems integration would be difficult, and so it was. (Project manager)

The plan for production preparations and ramp-up included a number of test series to ensure a smooth transition to production. However, due to previous delays, the engineers had to squeeze the test series, reducing the time for evaluation, learning and refinement. Notwithstanding these problems, respondents agree that the project was a success, primarily due to a positive market response and promising initial sales development. In retrospect, the project manager claimed that they could have foreseen challenges of systems integration. Still, the organization was not prepared to handle them. After project finalization, the senior managers saw the need to enhance the integrative capabilities of the R\&D department. Therefore, they established a new position in the organization: systems engineers with the task to assist specification in major projects.

\subsection{Automotive}

Automotive is a supplier of sports utility transportation equipment for cars, such as bike carriers, roof racks, and roof boxes. Automotive is a global market leader, but its most important markets are Europe and the US. The case study describes the development of a completely new generation of a high-end product within the tow bar mounted bike-carrier segment. Most customers use their bike carriers mainly during the summer and a delay of the project could affect the sales of bike carrier systems negatively. Therefore, the project had a strict deadline to deliver the product on time, right before the summer season, one and a half years after project start. The development included a number of new features, new materials, more advanced technological solutions and new coupling device. A completely new design gave the product a different appearance from that of its predecessors. The project manager identified particular uncertainties related to the new coupling device.

The coupling is incredibly difficult. It demands so many tests, driving tests, pulling tests and shake tests. It is actually quite stupid to design a coupling that can carry the load of three bikes at $60 \mathrm{~kg}$ on a car's tow bar.

\footnotetext{
${ }^{1}$ Sew fest is an annual event, which gathers a significant share of the North American dealer network and thus provides a valuable opportunity for product launch and feedback.
} 
Facing the task of having to develop and verify a new product concept, the project manager formed a co-located cross-functional team. The team included R\&D engineers, as well as representatives from purchasing, marketing, and production engineering. In addition, engineers from prototyping, assembly and industrial design supported the project. Initially, the team focused on evaluating the concept in informal meetings and brainstorming sessions.

At the outset, we did not consider specific modules but rather evaluated the overall product concept from different perspectives. Everybody provided specific input to improve the initial concept solution and create a basis to work further on. (Project Manager)

The project team gathered in weekly meeting to clear up major engineering challenges. On a daily basis, team members met to discuss and evaluate technological solutions and their implications on the complete product concept.

By discussing ideas with other team members, we can find new angles on problems. Sometimes new ideas can come up and you can question the solution by asking: "why have you designed like this"? (Project manager)

In one of the prototype tests, the project team encountered problems related to the coupling. When the team performed a so-called "sleeping policeman" test, i.e. driving over speed bumps with a fully loaded bike carrier, some of the components deformed and the coupling broke down. Consequently, the engineers had to re-iterate the product design and the team feared that this would result in a significant delay. To get the product ready, the project manager therefore decided to let individual components, rather than the complete product, pass design approval and start production engineering. In fact, the project bypassed the formal gate, allowing it to proceed even though the complete design still was not settled. The idea was to compress the project's final stages by ordering manufacturing tools before design freeze.

We struggled a lot in every corner of the project and it really was a tough job. We had to decide what we could produce and what we needed to delay a bit in order to create the time to make the changes. Formally, we were not ready to pass the checkpoint after the product-engineering stage. Then we released some of the plastic tools, which we thought would not be changed later on. The sheet metal tools were delayed, but when additional problems occurred we needed to start with them anyway. I decided, even with incomplete information, to start engineering the tools, keeping them 'on the shelf'. Some had to be modified afterwards, resulting in extra work, but others could be released immediately. Thus, we could save about 8 weeks. (Production Engineer)

The decision to bypass the gate was associated with significant risks, as the project team had to anticipate possible interface alterations. The project manager introduced separate weekly meetings for the different components. Additionally, also in weekly meetings, the entire project team discussed the status of the overall project. A specific product launch team took care of the main contacts with the production facility and coordinated the manufacturing of the pre-series. In the end, this approach was successful and Automotive released the new bike carrier system on the market right before the season. Whereas the decision to bypass the gate violated the firm's stage-gate model, this was necessary to complete the project in time. After the project, the management investigated possibilities to revise the stage-gate model to enable lead-time reduction by means of calculated risks at this particular gate. 


\section{Comparative analysis}

The studied projects faced a variety of uncertainties related to product concepts, interfaces, and individual components. Perceptions of the locus of uncertainty largely guided managers in facilitating different kinds of NPD processes. Throughout the different project-stages, additional challenges appeared, altering initial ideas and resulting in redefined processes.

\subsection{Patterns of NPD processes}

NPD stage-models suggest that early stages of development will serve to clarify product concepts and system characteristics (Eppinger, 1991; Ullman, 2010; Ulrich \& Eppinger, 2011). Thus, integrative processes will be more prevalent during early stages, and concurrent processes will be more prevalent during later stages. However, only one of the three cases Automotive - followed this pattern. In the Automotive case, uncertainty related to the unverified product concept resulted in a perceived need for integration up-front in the project. To support systems-level problem solving, the project team members were co-located and they held cross-functional and cross-system engineering meetings on a continuous basis. Daily routines based on an interactive way of working also facilitated integration. Nonetheless, disturbances and technical problems resulted in delays, and the situation eventually became untenable. To be able to complete the project in time, the project manager had to alter the development process. He based the altered process on an assumption that it was possible to consider the interfaces stable, thereby facilitating separate development paths for individual components, while still observing potential system-level problems.

The other two cases followed contrasting patterns. Outdoor faced a very demanding, specific, and non-negotiable objective. To reach this objective at the stipulated deadline, the project manager established separate module teams and concurrent processes at an early stage. This allowed the engine team to focus on their task, keeping disturbances at a minimum. A prerequisite for this was that engineers outside the engine team did not make any significant design changes. As suggested by (Danese \& Filippini, 2010), by means of modular product architecture it was possible to reduce development lead-times. However, as the Outdoor project turned its focus to production, the development task called for integration. Facilitating system-level learning and transfer of lessons back to product and production engineering, the test assembly line became the arena, around which the integrative process revolved. The shift from product to production development reflects how the scope of architectures may change during the course of a NPD project. A majority of the studies reported so far has analysed relationships between either product architectures and organisations or production systems and organisations (Campagnolo \& Camuffo, 2010). However, the underlying logic of products and production systems may not necessarily match (Fourcade \& Christophe, 2005; Sako, 2003; Takeishi \& Fujimoto, 2003). While it is possible to design modular product systems, production systems can be more complex and integral (and vice versa). Still, NPD projects have to address both. As illustrated by the Outdoor case, the transition from productto production-oriented stages of development may call for altered processes.

Also in the Home case, the project manager initially established separate module teams, which were to operate concurrently. Nevertheless, the rationale was very different from the Outdoor case. In the Home project the existing organisational structure, rather than the specific task requirements, determined the initial process. However, technical problems discovered in system-level tests eventually called for reconsideration. Brusoni et al. (2001) explain how unpredictable product interdependencies and uneven rates of change in component 
technologies will result in a need for systems integration. In the Home case, the dramatic increase of software content, the unpredicted disturbances of the electronics, and the implementation of new illumination technology with unclear implications for software development all indicate that the project incorporated both these factors. Notably, the challenge of systems integration did not come as a surprise, but the organisation was still not prepared to meet the challenge. As the need for systems integration became inevitable, the project manager therefore had to implement integrative processes on an ad hoc basis. Table 1 presents a summary of the analysis, outlining the prime rationale for different NPD processes in the case studies.

Table 1 Rationale for different NPD processes in the cases

\begin{tabular}{|l|l|l|}
\hline Automotive & Early development stages & Late development stages \\
\hline Outdoor & $\begin{array}{l}\text { New product concept }- \\
\text { Integrative process }\end{array}$ & $\begin{array}{l}\text { Stabilized interfaces - } \\
\text { Concurrent/Integrative process }\end{array}$ \\
\hline Home & $\begin{array}{l}\text { Stable product architecture - } \\
\text { Concurrent process }\end{array}$ & $\begin{array}{l}\text { Shift from product to production } \\
\text { focus - Integrative process }\end{array}$ \\
\hline $\begin{array}{l}\text { Existing organisational structure } \\
- \text { Concurrent process }\end{array}$ & $\begin{array}{l}\text { Systems integration challenges - } \\
\text { Integrative process }\end{array}$ \\
\hline
\end{tabular}

\subsection{Architectures as input to - and output from - NPD activities}

According to strategic management literature, it is possible to derive substantial benefits from modular product architectures, but this requires that NPD projects base their work on established architectures (Cabigiosu \& Camuffo, 2012). The Outdoor case serves as an illustration. By keeping the architecture stable, the project could focus its efforts on one particular task - significantly reduced emissions. For Outdoor, stable product architecture was a critical decision, which made it possible to complete the project on time.

By contrast, engineering design literature suggests that each NPD project should devote its early stages to product definition, concept development and systems design, investigating different technological options before settling the architecture (Ullman, 2009; Ulrich \& Eppinger, 2011). The Automotive case illustrates this. Here, the project assignment included a new technological concept and the engineers thus spent extensive time initially on conceptual elaboration, evaluation and verification. However, as the project ran into delays, the project manager had to reconsider. The presumption that interfaces would not change made it possible to bypass the formal design approval, which was supposed to function as an integration point. However, to be able to manage the project like this, the project manager had to obtain extensive authority within his organization.

The conflicting propositions of strategic management and engineering design literature appear to build on different assumptions about NPD projects and the organizational context in which they operate. Whereas strategic management literature assumes that engineers base their work in NPD projects on established product architectures, engineering design literature assumes that NPD projects have full discretion to take independent decisions. As illustrated by the Automotive and Outdoor cases, either of these assumptions may be valid. Hence, these two cases appear as extremes in terms of, on the one hand, adherence to pre-specified architectures (Outdoor), and on the other hand, project independence and authority (Automotive). In this respect, the third case (Home) may illustrate an intermediate and perhaps more normal situation for NPD. Although this project comprised new challenges in terms of systems integration, the existing $\mathrm{R} \& \mathrm{D}$ organization - reflecting the established product 
architecture - still served as a blueprint for project organization. However, the existing organization did not comprise the required integrative capabilities needed for project execution. To be able to solve the integration problems that eventually appeared, the project had to define alternative structures and processes. Hence, this case demonstrates a more complex relationship between product architectures and organizations, where the architecture takes a dual role of being both input to, and output from, NPD (cf. Brusoni \& Prencipe, 2011; Sushandoyo \& Magnusson, 2012).

\subsection{The effects of time pressure}

A recurrent theme that emerges from the case studies is the effects of time pressure. All projects felt pressure to deliver within reasonable time. Still, they perceived this pressure differently, and the current understanding of the architecture filled an important role in the formulation of responses. In the Outdoor case, the strong initial discipline and focus seem to have relieved the project from extensive time pressure during the later stages. By contrast, disturbances and technical problems amplified the time pressure in the Home and Automotive cases. In both the Automotive and the Outdoor case, reliance on modular product architectures was an explicit strategy to cope with time pressure, albeit during different stages. By considering the architecture modular during certain project stages, it was possible to save time by means of concurrent processes. However, the opposite is also possible. As illustrated by the Home case, initial ideas of modular architectures may prove to be invalid due to technical problems. Such problems may be merely reflections of the dynamic character of product development, but they can nevertheless constitute important triggers for organizational change.

\section{Conclusion}

With the aim to explore the operational aspects of product architectures in NPD, this paper has shown how product architectures evolve in conjunction with dynamic processes of integration and separation in NPD projects. Notwithstanding their evolving properties, product architectures can serve to guide NPD processes. As illustrated by our case studies, new technological options and concepts, accelerated development of component technologies, unexpected results from prototype tests, and transitions from product- to production-oriented stages of development may expose NPD projects to significant challenges. Enhanced deadlines and pressure to deliver will aggravate these challenges. The case study analysis shows how product architectures function as schemes of interpretation, which project managers use to connect the learning that takes place within NPD projects with exogenous forces that prompt action and reaction. Positioning the product architecture along the integral - modular scale means that it is possible to question the validity of existing organizational structures and routines. Thus, assessing the characteristics of product architectures help managers devise appropriate responses to perceived challenges in NPD.

However, the ability to manage new product development does not merely hinge on simple assessment and positioning of the product architecture and its associated NPD process. The inherent uncertainty of NPD implies that any such assessment will be imperfect. Even a project that has a task to develop what appears to be a modular system may run into problems, which call for integrative processes; and even a project with a task to develop a seemingly integral system may experience time pressure, which necessitate concurrent processes. Building a preparedness to alter its process thus appears to be critical for any NPD project. For this reason, repeated questioning of the rationale that justifies the current process, as well 
as the assumptions behind this rationale, is essential. Providing useful linkages between knowledge development and organizational change, product architectures fill an important role in this repeated questioning.

\section{Acknowledgements}

We are grateful for the constructive comments received from two anonymous referees and the Associate Editor Jonathan Aylen. Stefano Brusoni and our colleagues in the Kite research team also provided helpful comments on early drafts. The case studies were conducted in collaboration with Kristina Säfsten and Glenn Johansson. The research received financial support from Vinnova and Riksbankens Jubileumsfond.

\section{References}

Baldwin, C. Y. and Clark, K. B. (1997) Managing in an age of modularity. Harvard Business Review, 75, 84-93.

Becker, M. C. and Zirpoli, F. (2003) Organizing new product development - Knowledge hollowing-out and knowledge integration - the FIAT Auto case. International Journal of Operations \& Production Management, 23, 1033-1061.

Brusoni, S. and Prencipe, A. (2011) Patterns of modularization: The dynamics of product architecture in complex systems. European Management Review, 8, 67-80.

Brusoni, S., Prencipe, A. and Pavitt, K. (2001) Knowledge specialization, organizational coupling, and the boundaries of the firm: Why do firms know more than they make? Administrative Science Quarterly, 46, 597-621.

Cabigiosu, A. and Camuffo, A. (2012) Beyond the "mirroring" hypothesis: Product modularity and interorganizational relations in the air conditioning industry. Organization Science, 23, 686-703.

Campagnolo, D. and Camuffo, A. (2010) The Concept of Modularity in Management Studies: A Literature Review. International Journal of Management Reviews, 12, 259-283.

Colfer, L. and Baldwin, C. Y. (2010) The mirroring hypothesis: Theory, evidence and exceptions. Harvard Business School Finance Working Paper.

Cooper, R. G. (1994) Perspective third-generation new product processes. Journal of Product Innovation Management, 11, 3-14.

Cooper, R. G. (2008) Perspective: The Stage-Gate® Idea-to-Launch Process - Update, What's New, and NexGen Systems. Journal of Product Innovation Management, 25, 213-232.

Danese, P. and Filippini, R. (2010) Modularity and the impact on new product development time performance: Investigating the moderating effects of supplier involvement and interfunctional integration. International Journal of Operations \& Production Management, 30, 1191-1209.

Dougherty, D. (1992) A practice-centered model of organizational renewal through product innovation. Strategic Management Journal, 13, 77-92.

Eisenhardt, K. M. and Tabrizi, B. N. (1995) Accelerating Adaptive Processes - Product Innovation in the Global Computer Industry. Administrative Science Quarterly, 40, 84-110.

Enberg, C., Lindkvist, L. and Tell, F. (2006) Exploring the Dynamics of Knowledge Integration Acting and Interacting in Project Teams. Management Learning, 37, 143-165.

Engwall, M. (2003) No project is an island: linking projects to history and context. Research Policy, 32, 789-808.

Eppinger, S. D. (1991) Model-based Approaches to Managing Concurrent Engineering. Journal of Engineering Design, 2, 283-290. 
Ethiraj, S. K. and Levinthal, D. (2004) Modularity and Innovation in Complex Systems. Management Science, 50, 159-173.

Filippini, R., Salmaso, L. and Tessarolo, P. (2004) Product development time performance: Investigating the effect of interactions between drivers. Journal of Product Innovation Management, 21, 199-214.

Fourcade, F. and Christophe, M. (2005) The role of 1st tier suppliers in automobile product modularisation: the search for a coherent strategy. International Journal of Automotive Technology Management, 5, 146-165.

Gibbert, M., Ruigrok, W. and Wicki, B. (2008) What passes as a rigorous case study? Strategic Management Journal, 29, 1465-1474.

Grant, R. M. (1996) Toward a Knowledge-Based Theory of the Firm. Strategic Management Journal, 17, 109-122.

Iansiti, M. (1995) Technology integration: Managing technological evolution in a complex environment. Research Policy, 24, 521-542.

Ingvarsson Munthe, C., Uppvall, L., Engwall, M. and Dahlén, L. (2014) Dealing with the devil of deviation: managing uncertainty during product development execution. $R \& D$ Management, 44, 203-216.

Kessler, E. H. and Chakrabarti, A. K. (1999) Speeding up the pace of new product development. Journal of Product Innovation Management, 16, 231-247.

Kusiak, A. (2002) Integrated product and process design: A modularity perspective. Journal of Engineering Design, 13, 223-231.

Lakemond, N; Magnusson, T; Johansson, G; Säfsten, K (2013): Assessing interface challenges in product development projects, Research technology management, 56(1), 4048

Lynn, G. S., Abel, K. D., Valentine, W. S. and Wright, R. C. (1999) Key factors in increasing speed to market and improving new product success rates. Industrial Marketing Management, 28, 319-326.

MacCormack, A., Baldwin, C. and Rusnak, J. (2012) Exploring the duality between product and organizational architectures: A test of the "mirroring" hypothesis. Research Policy, 41, 1309-1324.

Marsh, S. J. and Stock, G. N. (2006) Creating Dynamic Capability: The Role of Intertemporal Integration, Knowledge Retention, and Interpretation. Journal of Product Innovation Management, 23, 422-436.

Mikkola, J. H. (2003) Modularity, component outsourcing, and inter-firm learning. $R \& D$ Management, 33, 439-454.

Mikkola, J. H. (2006) Capturing the Degree of Modularity Embedded in Product Architectures. Journal of Product Innovation Management, 23, 128-146.

Miles, M. B. and Huberman, A. M. (1994) Qualitative data analysis : an expanded sourcebook. Thousand Oaks, CA: Sage.

Nightingale, P. (2000) The product-process-organisation relationship in complex development projects. Research Policy, 29, 913-930.

Okhuysen, G. A. and Eisenhardt, K. M. (2002) Integrating knowledge in groups: How formal interventions enable flexibility. Organization Science, 13, 370-386.

Orton, J. D. and Weick, K. E. (1990) Loosely Coupled Systems - a Reconceptualization. Academy of Management Review, 15, 203-223.

Ro, Y. K., Liker, J. K. and Fixson, S. K. (2007) Modularity as a strategy for supply chain coordination: The case of US auto. Ieee Transactions on Engineering Management, 54, 172-189.

Sako, M. (2003) Modularity and outsourcing. In: Davies, A. and Hobday, M., eds. The business of systems integration. Oxford: Oxford University Press, 229-253. 
Sanchez, R. and Mahoney, J. T. (1996) Modularity, flexibility, and knowledge management in product and organization design. Strategic Management Journal, 17, 63-76.

Simon, H. A. (1962) The architecture of complexity. Proceedings of the American Philosophical Society, 467-482.

Stockstrom, C. and Herstatt, C. (2008) Planning and uncertainty in new product development. $R \& D$ Management, 38, 480-490.

Sushandoyo, D. and Magnusson, T. (2012) A two-way relationship between multi-level technological change and organisational characteristics-cases involving the development of heavy hybrid buses. Technovation, 32, 477-486.

Takeishi, A. and Fujimoto, T. (2003) Modularization in the car industry: interlinked multiple hierarchies of product, production and supplier systems. In: Prencipe, A. and Hobday, M., eds. The business of systems integration. Oxford: Oxford University Press, 254-278.

Ullman, D. (2009) The mechanical design process. New York, NY: McGraw-Hill.

Ulrich, K. (1995) The role of product architecture in the manufacturing firm. Research Policy, 24, 419-440.

Ulrich, K. and Eppinger, S. (2011) Product design and development. New York, NY: McGraw-Hill/Irwin.

Vincenti, W. G. (1990) What engineers know and how they know it: Analytical studies from aeronautical history. Baltimore, Md.: The Johns Hopkins University Press

Yin, R. K. (1994) Case study research: Design and methods. California: SAGE Publications, Inc.

Zirpoli, F. and Becker, M. C. (2011) The limits of design and engineering outsourcing: performance integration and the unfulfilled promises of modularity. $R \& D$ Management, 41, 21-43. 